\title{
ROLE OF COMBINING COLOUR DOPPLER WITH ULTRASONOGRAPHY IN THE EVALUATION OF ADNEXAL MASSES
}

\author{
Kambham Suhasini ${ }^{1}$, Lakshmi Garuda², Sabitha $C^{3}$
}

${ }^{1}$ Associate Professor, Department of Obstetrics and Gynaecology, CKM Govt. Maternity Hospital \& Kakatiya Medical College, Warangal. ${ }^{2}$ Associate Professor, Department of Obstetrics and Gynaecology, CKM Govt. Maternity Hospital \& Kakatiya Medical College, Warangal. ${ }^{3}$ Post Graduate, Department of Obstetrics and Gynaecology, CKM Govt. Maternity Hospital \& Kakatiya Medical College, Warangal.

\section{ABSTRACT}

\section{PURPOSE}

To evaluate the appropriateness of combining colour Doppler with gray scale ultrasonography in suspicious adnexal masses. To evaluate the efficacy of this combination in differentiation of benign and malignant masses compared to 2D Gray Scale Ultrasonography alone.

\section{METHODS}

Forty six patients with suspicious adnexal masses were evaluated. Morphological characterisation of the masses was done by Sassone Scoring. Colour Doppler parameters were noted and Caruso scoring done. The results were compared to surgical and histopathological findings.

\section{RESULTS}

Using Sassone Scoring, overall reliability of differentiating adnexal masses had sensitivity of $85 \%$ and specificity of $76 \%$. By using Caruso scoring a sensitivity of $85 \%$, specificity of $90 \%$ was obtained. By combining sonomorphological score with Doppler indices, specificity increased to $80.9 \%$, PPV increased from $63 \%$ to $70.3 \%$.

\section{CONCLUSION}

In evaluation of adnexal masses combining Doppler indices with morphological scores gave higher specificity and positive predictive value.

\section{KEYWORDS}

Adnexal Masses. Gray Scale Ultrasonography, Colour Doppler, Malignant, Benign.

HOW TO CITE THIS ARTICLE: Kambham Suhasini, Lakshmi Garuda, Sabitha C. "Role of Combining Colour Doppler with Ultrasonography in the Evaluation of Adnexal Masses." Journal of Evolution of Medical and Dental Sciences 2015; Vol. 4, Issue 97, December 03; Page: 16266-16272, DOI: 10.14260/jemds/2015/2398

\section{INTRODUCTION}

Adnexal masses are a common clinical problem. The discrimination between benign and malignant adnexal masses is central to decisions regarding clinical management and surgical planning in such patients. ${ }^{1}$

A standardized method for preoperative identification of malignant masses would allow management of ovarian cancer in ideal circumstances with appropriate preoperative counselling to patient and attendants. Examination of the patient clinically has poor sensitivity (15-51\%) in detection of ovarian cancer.(2) To improve the survival rate in ovarian cancer, it is necessary to manage such cases in a speciality service of Gynaecological Oncology.(3)

Benign masses although found to be complex by ultasonography mostly remain unchanged during long-term followup. Therefore, it is possible to manage these lesions safely by ultrasound followup rather than surgical

Financial or Other, Competing Interest: None

Submission 09-11-2015, Peer Review 10-11-2015,

Acceptance 24-11-2015, Published 03-12-2015.

Corresponding Author:

Kambham Suhasini,

6/B, Sampati Apts., 6-3-855/10/A,

Ameerpet-500016,

Hyderabad.

E-mail: kambhamsuhasini@gmail.com

DOI:10.14260/jemds/2015/2398 intervention in asymptomatic women and the options can be explained to the patient. ${ }^{1}$

Morphological analysis of adnexal masses with grey scale imaging can help narrow the differential diagnosis between benign and malignant masses. "Pattern recognition of certain ultrasound findings has high sensitivity and specificity in diagnosing ovarian malignancies." $(4,5)$ This can reduce unnecessary laparotomies.(6)

Recent studies have shown that grey scale USG when combined with colour Doppler discriminates benign from malignant masses with higher sensitivity and specificity. Hence, in the present study, we attempted to analyse the results of the study correlating them with both surgical and histopathology reports to prove their efficacy in differentiating malignant from benign masses.

Malignant neoplasms have active blood vessel creation (Angiogenesis) compared to normal or benign neoplasms in part due to their increased metabolic activity. Overall, malignancies display an increased vascularity with decreased peripheral blood flow resistance and increased blood flow velocity. Doppler analysis can separate high resistance and low resistance vessels and has been investigated as an imaging modality in evaluation of adnexal masses. Distribution and pattern of the vessels as detected by colour Doppler has been given importance in most studies.(7) 


\section{MATERIAL AND METHODS}

The study was done in CKM Hospital, a Tertiary Teaching Hospital in Warangal. Patients with significant adnexal masses in reproductive, perimenopausal and postmenopausal age groups were recruited from Outpatient Department and referred cases from periphery were also included. Some of the patients presented with clinical symptoms like pain abdomen or mass abdomen and some were incidentally diagnosed during ultrasonography.

\section{Inclusion Criteria}

- Patients in reproductive, perimenopausal and postmenopausal age groups.

- Complex adnexal masses of $5 \mathrm{~cm}$ or more.

\section{Patients excluded from the study were those with:}

- Ectopic pregnancy.

- $\quad$ Surgical causes of pelvic masses.

- Obvious malignant masses with metastases.

Written and informed consent were taken from the patient. Initially patients were subjected to gray scale ultrasound examination and then subjected to Doppler studies.

In a study period of one and a half years from $1^{\text {st }}$ September 2013 to 28 ${ }^{\text {th }}$ February 2015, we evaluated 46 patients with 62 masses (Some patients had bilateral masses). They were prospectively evaluated by B-mode ultrasonography, Colour and Spectral Doppler study using a transvaginal sonography using 6-9Mhz. We performed transabdominal sonography using a $3-5 \mathrm{Mhz}$ sector transducer where necessary depending on the size and situation of the masses. The colour Doppler scoring and spectral indices (RI, PI) were noted and characterisation of the masses done by Sassone Score (Table 1) and Caruso Score (Table 2) and results correlated with surgical and histopathology findings.

Morphological scoring is done using Sassone Score [Table 1], where a score $\geq 9$ is considered to be probably malignant.

A Caruso score of $\geq 5$ was considered indicative of malignancy. Doppler parameters are optimized for detection and calculation of impedance indices. Flow results were recorded as being absent or present and further characterized as normal or increased and central or peripheral. On spectral Doppler, the lowest RI, PI detected at any point in the mass was used for analysis.

The cut-offs taken for spectral Doppler indices are as follows:

$$
\left.\begin{array}{l}
\mathrm{RI}=<0.4 .(8) \\
\mathrm{PI}=<1 .{ }^{(9)} \\
\mathrm{PSV}=>15 \mathrm{~cm} / \mathrm{sec}_{.}(10)
\end{array}\right\} \text { Indicative of Malignancy }
$$

The combination of grey scale ultrasonography and colour Doppler was evaluated and sensitivity, specificity, PPV, NPV and P-values are calculated. The study is compared with other standard studies and ROC graph plotted (Figure-9).

\section{RESULTS}

Out of 46 patients evaluated, 30 were pre-menopausal and 16 were postmenopausal; $65 \%$ of adnexal masses were noted in pre-menopausal age group. Out of the $35 \%$ in postmenopausal women, $50 \%$ of the masses were found to be malignant (Figure 6a and 6b).

When incidence of suspicious adnexal masses according to parity was noted, incidence was more among Para 2 and Para 3 (Table 3 and Figure 7), probably because the number of Para 2 and Para 3 women was more. Of the 62 masses noted in 46 patients, 20 were malignant and 42 were benign.

The distribution of various masses according to histopathologyis shown in [Table 4] [Table 5]: By applying Sassone score, masses suspicious of malignancy $\geq 9$ were $(n=27)$, of which 17 were malignant. Sassone score had sensitivity of $85 \%$, specificity of $76 \%$, positive predictive value of $63 \%$ and negative predictive value $91 \% .(10),(11)$ Although the $\mathrm{P}$ values (Calculated using Chi square) were significant, specificity was lower and also high false positive rate was found with USG.

Applying Caruso score, the sensitivity was 85\%, specificity 90\%, PPV $80.9 \%$, NPV 92.6\%. The combination using Sassone score $>9$, Caruso score $>5$ is found in 20 masses, of which 16 were malignant $(\mathrm{P}=0$.). Sensitivity of the combination was $95 \%$, specificity was $80.9 \%$, positive predictive value $70.3 \%$, negative predictive value $97 \%$ (Figure 6).

Presence of flow is noted in 18(95\%) out of 20 malignant masses. Presence of central vascularity in apparently solid regions and septal regions was seen in 16 out of 20 malignant masses ( $P$ value $<0.05$ ) showing significance of central vascularity rather than simple presence of flow [Table 6] (Timmerman, et al. 2012).

Using spectral indices, RI $<0.4$ is seen in 12 out of 20 malignant masses ( $\mathrm{P}$ value $<0.0005$ ). $\mathrm{PI}<1$ seen in $11 / 20$ malignant masses and 18/42 benign masses ( $\mathrm{P}$ value $>0.05$ ).

\section{DISCUSSION}

Currently ultrasound is the preliminary and most commonly used diagnostic tool in the clinical setting of evaluation of adnexal masses. Ultrasound imaging has higher sensitivity, but due to poor specificity cannot be used in differentiating benign and malignant masses and is not reliable to obviate more invasive procedures. Colour Doppler imaging and spectral Doppler imaging have been investigated as possible means of improving specificity of gray scale sonography in differentiating benign and malignant masses.

Although only 20 were histopathologically proven to be malignant masses (Including 5 borderline masses), using Sassone score a total of 26 masses had a score of $>9$ of which 18 were proved to be malignant. The high scoring lesions were endometriomas, dermoids (Figure 3a and b) and tubal masses (Mostly inflammatory).(12)

Solid component within a cystic mass is the most important predictor of malignancy and conversely, malignancy is very unlikely in the absence of a solid component.[13] It also includes papillary projections, excrescences, vegetations, and nodules. Small solid areas that protrude more from the internal surface of the cyst wall are considered as papillary projections.[14] Papillary projections, for example a solid projection into a cyst cavity from the cyst wall of more than $3 \mathrm{~mm}$ in height.[15] are a strong sign of malignancy.[16-20] Papillary projections also occur in some serous (Figure 2a) and mucinous cystadenomas and cystadenofibromas. 
Septa in a cystic ovarian mass are strong evidence of a neoplasm.(21) mostly when they are greater than $2-3 \mathrm{~mm}$ in thickness or have detectable flow on Doppler USG scans.(22) Figure (5) A cystic mass with multiple, smooth, thin septa and no nodularity is suggestive of a mucinous cystadenoma.[23]

Some of the features which helped in ultrasonography in determining malignancy are shown in Figure (2) i.e., presence of thick septa, papillary projections, heterogenous echotexture.(24) Benign tumours were characterised by unilocularity, thin septae, isoechogenicity and thin walled capsule.

In Doppler scores it is the presence of central vascularity $(p<0.05)$, which is important than just noting down the presence of flow in masses.

Using RI alone is not sufficient as there is considerable overlap between benign and malignant masses. The RI cut-off value used has a significant $\mathrm{p}$-value $(<0.0005)$.

Pulsatility index $<1.0$ had a lower sensitivity and specificity and there is a significant overlap between malignant and benign masses.

In the present study, B mode ultrasonography along with Doppler predicts benignity of tumour reliably as well as only 6(14.2\%) masses were misdiagnosed. Thus, multiparameter analysis utilizing B mode gray scale USG with colour and spectral Doppler offers good sensitivity, specificity and positive predictive value (Figure-8). It should always be the diagnostic modality of choice in patients with adnexal masses as it is easy to use, easily available, cheap and results are reproducible.

When compared with other studies as shown in Figure 9 , our study had a false positive rate of $19 \%$, which is nearer to Alcazar et al., Valentin et al. This high false positive rate may be because of the interobserver variability.

IOTA study started in 1999 is still ongoing. This study used multiple parameters useful in determining the nature of ovarian masses. They developed logistic regression models LR1 and LR2 where many variables are studied to differentiate benign and malignant masses, based on demographic and USG and Doppler findings. They also developed simple rules to assess these masses ultrasonographically and help in differentiating benign from malignant.

Parameters used in the main IOTA regression model are shown in (Table 7). There is scope in this study for ongoing research to develop a universal scoring system. This could help in more reliable diagnosis and treatment.

MRI is a valuable problem-solving tool when USG is inconclusive. Recent evidence supports the implementation of diffusion- or perfusion-weighted imaging in addition to conventional MR pulse sequences.

Another recent study showed that 3D power Doppler assessment of solid tumour areas or papillary projections reduced the false positive rate of complex cystic benign adnexal masses and increased sensitivity rate to $99 \%$. Contrast enhanced, 3D power Doppler sonography allows better visualization of tumor vascularity in suspicious adnexal lesions than that obtained with non-contrast enhanced 3D power Doppler sonography.(25)

\section{RESEARCH AND FUTURE POSSIBILITIES}

Development of technology in future and introduction of "3D quantification of blood flow" called "the 3D colour histogram," may improve differentiation between benign and malignant ovarian tumors.(26-28) Microbubble enhanced transvaginal sonography is also being tried to improve the diagnosis of malignant masses by early detection of tumour microvascularity. Using microbubbles that are small enough to pass through capillaries, the kinetics of the blood flow can be analysed to detect abnormal flow found in areas of neovascularisation.[29]

This has the potential for the detection and quantification of tumour angiogenesis at the molecular level. In a recent study, ultrasonographic microbubbles targeted with one of several antibodies (Anti-vascular endothelial growth factor receptor 2 and others) were injected into mice with implanted ovarian tumours. As the tumours grew, changes in the relative uptake of each targeted microbubble were observed, opening up the possibility of non-invasive in vivo molecular profiling of tumour angiogenesis as a diagnostic tool.[30]

\section{CONCLUSION}

Relying on the accuracy of gray scale morphologic assessment alone without colour Doppler imaging is less reliable. Both modalities lack sufficient specificity and predictive values if used alone to detect malignancy.

Thus a multi parameter analysis which incorporates morphologic scoring, vessel location, and arrangement and pulsed doppler waveform characteristics would be a better tool in differentiating malignant from benign lesions. This will guide us in determining patients in whom early intervention is necessary versus those in whom an expectant management may be undertaken.

\begin{tabular}{|c|c|c|c|c|c|}
\hline $\begin{array}{c}\text { USG } \\
\text { Finding }\end{array}$ & 1 & 2 & 3 & 4 & 5 \\
\hline $\begin{array}{c}\text { Inner } \\
\text { wall } \\
\text { structure }\end{array}$ & smooth & $\begin{array}{c}\text { Irregula } \\
\text { rity }<3 \mathrm{~m} \\
\mathrm{~m}\end{array}$ & $\begin{array}{l}\text { Papillaritie } \\
\mathrm{s}>3 \mathrm{~mm}\end{array}$ & $\begin{array}{c}\text { Not } \\
\text { applica } \\
\text { ble }\end{array}$ & - \\
\hline Septae & $\begin{array}{c}\text { No } \\
\text { septa }\end{array}$ & $\begin{array}{c}\text { Thin }<3 \\
\text { mm }\end{array}$ & $\begin{array}{c}\text { Thick }>3 \mathrm{~m} \\
\mathrm{~m}\end{array}$ & - & - \\
\hline $\begin{array}{c}\text { Wall } \\
\text { thickness }\end{array}$ & $\begin{array}{c}\text { Thin<3 } \\
\mathrm{mm}\end{array}$ & $\begin{array}{c}\text { Thick }>3 \\
\text { mm }\end{array}$ & $\begin{array}{c}\text { Not } \\
\text { applicable } \\
\text { mostly } \\
\text { solid }\end{array}$ & - & - \\
\hline $\begin{array}{l}\text { Echogeni } \\
\text { city }\end{array}$ & $\begin{array}{c}\text { Sonoluc } \\
\text { ent }\end{array}$ & $\begin{array}{l}\text { Low } \\
\text { echoge } \\
\text { nic }\end{array}$ & $\begin{array}{l}\text { Low } \\
\text { echogenic } \\
\text { with } \\
\text { echogenic } \\
\text { core }\end{array}$ & $\begin{array}{l}\text { Mixed } \\
\text { echoge } \\
\text { nicity }\end{array}$ & $\begin{array}{l}\text { High } \\
\text { echogeni } \\
\text { city }\end{array}$ \\
\hline
\end{tabular}

\begin{tabular}{|c|c|c|}
\hline Criteria & Score \\
\hline \multirow{2}{*}{ Vessels } & Absent & 0 \\
& Present & 1 \\
\hline \multirow{3}{*}{ Vessels location } & Peripheral & 0 \\
& Septal & 1 \\
& Central & 2 \\
\hline Arrangement of & Regular & 0 \\
vessels & Random & 2 \\
\hline \multirow{2}{*}{ Waveform pattern } & Sharp with & 0 \\
& diastolic notch & 2 \\
\hline \multicolumn{2}{|c|}{ Smooth without } & 0 \\
\hline \multirow{2}{*}{ Lowest RI } & notch & 2 \\
\hline
\end{tabular}




\begin{tabular}{|c|c|c|}
\hline Parity & Number of pts. & Incidence(Approx.) \\
\hline Nullipara & 6 & $14 \%$ \\
\hline P 1 & 4 & $9 \%$ \\
\hline P2 & 11 & $26 \%$ \\
\hline P3 & 15 & $35 \%$ \\
\hline P4 & 7 & $16 \%$ \\
\hline P5 & 2 & $5 \%$ \\
\hline P6 & 1 & $2 \%$ \\
\hline \multicolumn{2}{|c|}{ Table 3 } \\
\hline
\end{tabular}

\begin{tabular}{|c|c|c|}
\hline Type of Masses & Number & $\begin{array}{c}\text { \% of the Total } \\
\text { Benign Masses } \\
\text { (approx.) }\end{array}$ \\
\hline Serous & 17 & $40 \%$ \\
cystadenoma & 6 & $14.2 \%$ \\
Mucinous & 6 & $9 \%$ \\
cystadenoma & 4 & $14.2 \%$ \\
Dermoid cysts & 6 & $7.1 \%$ \\
Endometriosis & 3 & $7 \%$ \\
Haemorrhagic & 3 & $4 \%$ \\
cysts & 2 & $2 \%$ \\
Tubal cysts & 1 & $2 \%$ \\
Serous cysts & 1 & \\
Fibroma & \multicolumn{2}{|c|}{ Table 4: Benign Masses } \\
Epidermoid cysts & (Histopathology)
\end{tabular}

\begin{tabular}{|c|c|c|}
\hline Type of Masses & Number & $\begin{array}{c}\text { \% of the Total } \\
\text { Malignant } \\
\text { Masses } \\
\text { (approx.) }\end{array}$ \\
\hline Serous cystadenocarcinoma & 6 & $30 \%$ \\
Mucinous cystadenoma & 7 & $35 \%$ \\
Borderline serous & 2 & $10 \%$ \\
Borderline mucinous & 2 & $10 \%$ \\
Endometroidadenocarcima & 1 & $5 \%$ \\
Granulosa cell tumour & 1 & $5 \%$ \\
Borderline endometroid & 1 & $5 \%$ \\
\hline \multicolumn{2}{|c|}{ Table 5: Malignant Masses } \\
(Histopathology) \\
\hline
\end{tabular}

\begin{tabular}{|c|c|c|c|}
\hline Criterion & Sonomorphology & $\begin{array}{c}\text { Combined } \\
\text { Colour } \\
\text { Doppler }\end{array}$ & $\begin{array}{c}\text { Conomorpho- } \\
\text { logy } \\
\text { and Colour } \\
\text { Doppler }\end{array}$ \\
\hline Sensitivity & $85 \%$ & $85 \%$ & $95 \%$ \\
\hline Specificity & $76 \%$ & $90.4 \%$ & $80.9 \%$ \\
\hline PPV & $63 \%$ & $80.9 \%$ & $70.3 \%$ \\
\hline NPV & $91 \%$ & $92.6 \%$ & $97 \%$ \\
\hline P value & $<0.05$ & $<0.0001$ & 0.0001 \\
\hline \multicolumn{3}{|c|}{ Table 6 } \\
\hline
\end{tabular}

$\mathrm{P}$ value calculated using $\mathrm{x} 2$ and exact test.

- Age

- Personal h/o ovarian cancer

- Largest diameter of the lesion

- Presence of ascites

- Presence of flow in papillary projection

- Irregular internal cyst walls

- Presence of a purely solid tumour

- Colour score

- Presence of acoustic shadows

- Current hormonal therapy

- Pain during examination Table 7: Variables used in IOTA Study

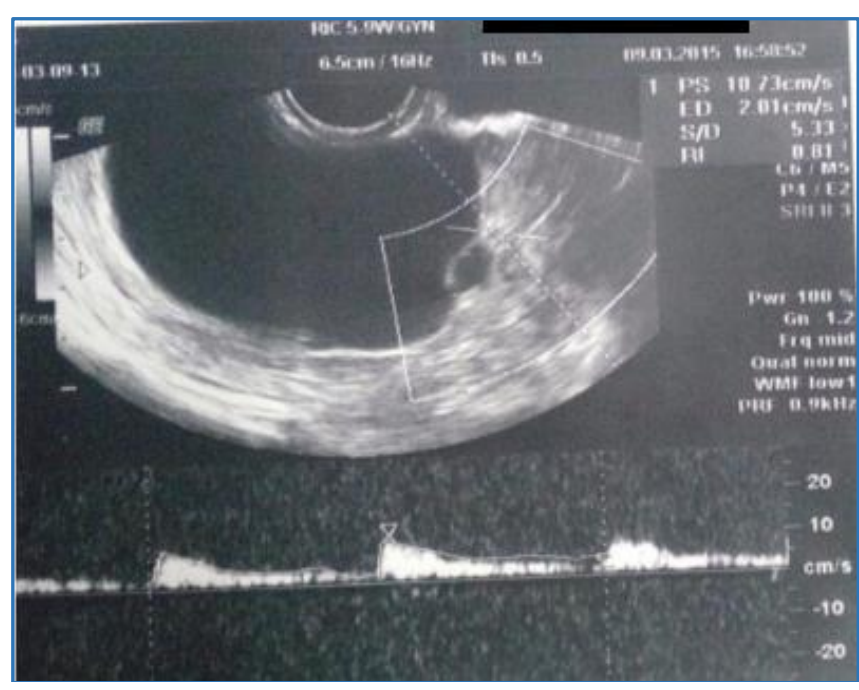

Fig. 1: A Patient with Serous Cystadenoma shows a Cystic Mass with Thin Septa. Only Peripheral Flow Identified in the Mass (Sassone Score <9; Caruso Score <5)

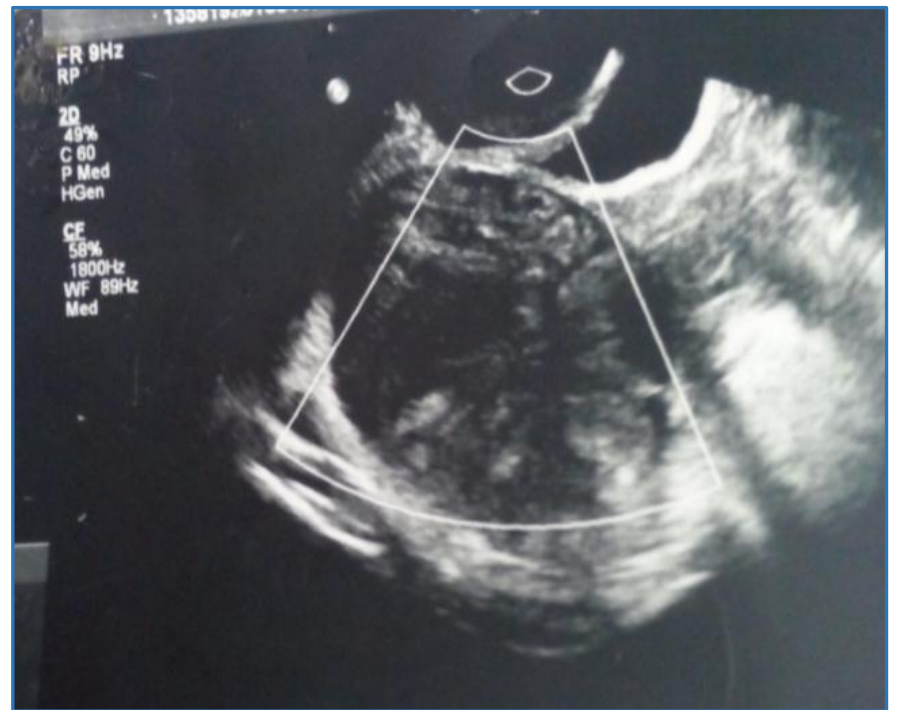

Fig. 2: A Patient with Solid and Cystic Mass with Thick Septa and Multiple Projections Suggestive of Malignancy. HPE Report was Endometroid Adenocarcinoma of Ovary 


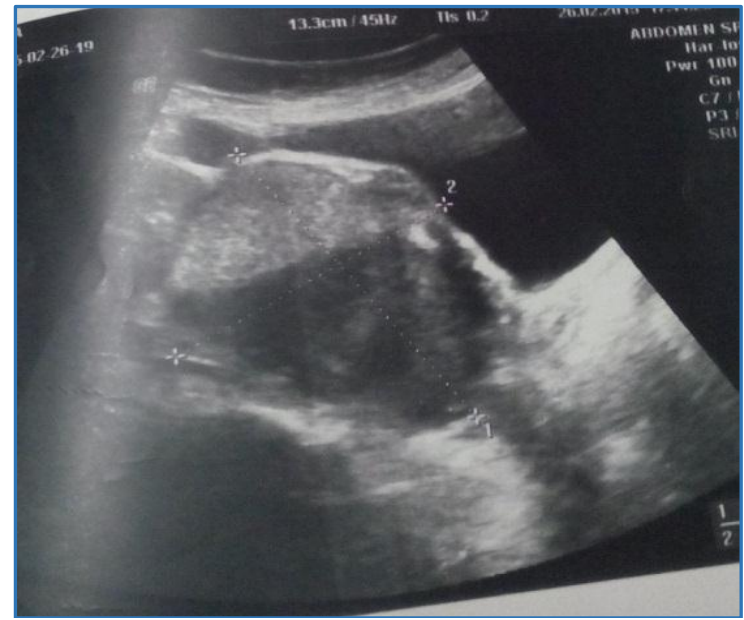

Fig. 3(a): USG of Dermoid showing Tip of Ice Berg Sign; (Hyperechoic Area - the Base of Which Cannot be Visualised, this is the Result of Mass Made Up of Matted Hair and Sebum Casting an Echogenic Shadow)

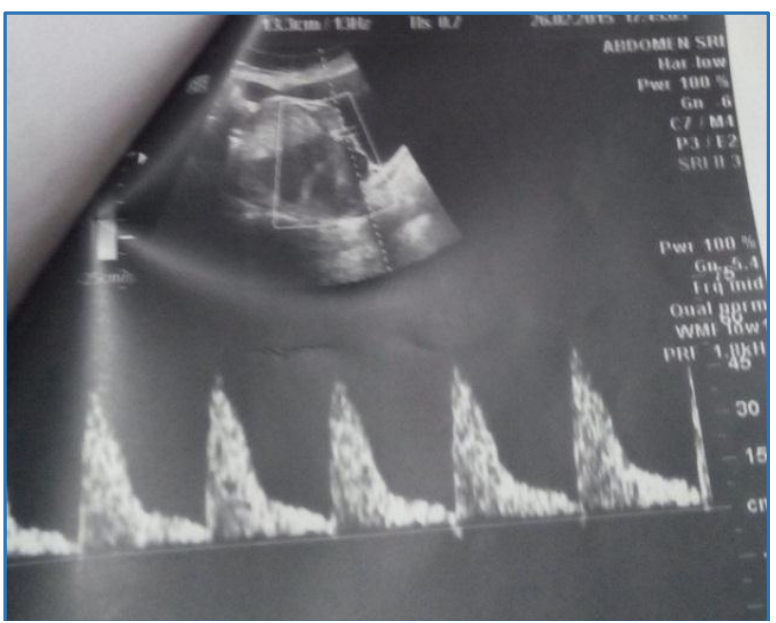

Fig. 3(b): Dermoid Cyst showing Absence of Flow on Doppler

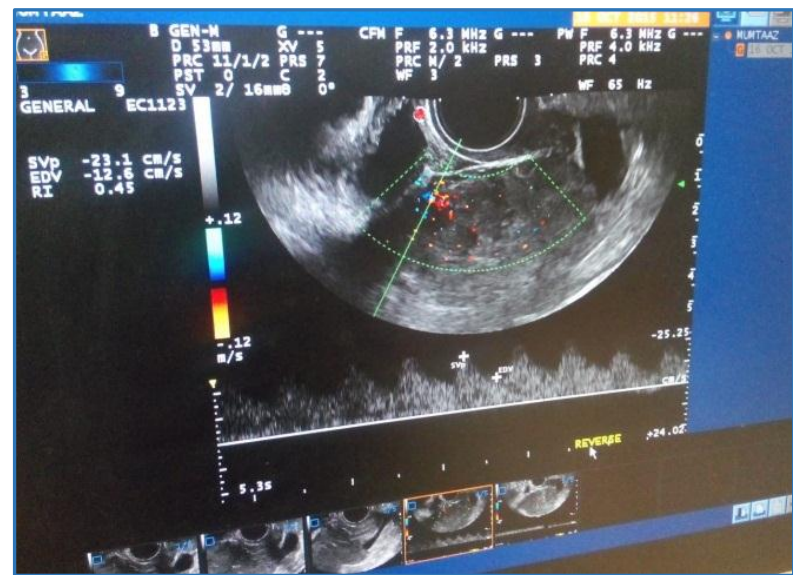

Fig. 4: A Case of Serous Cystadenocarcinoma with Doppler showing Increased Flow Within Tumour with Low Resistant Index Characteristic of Malignancy

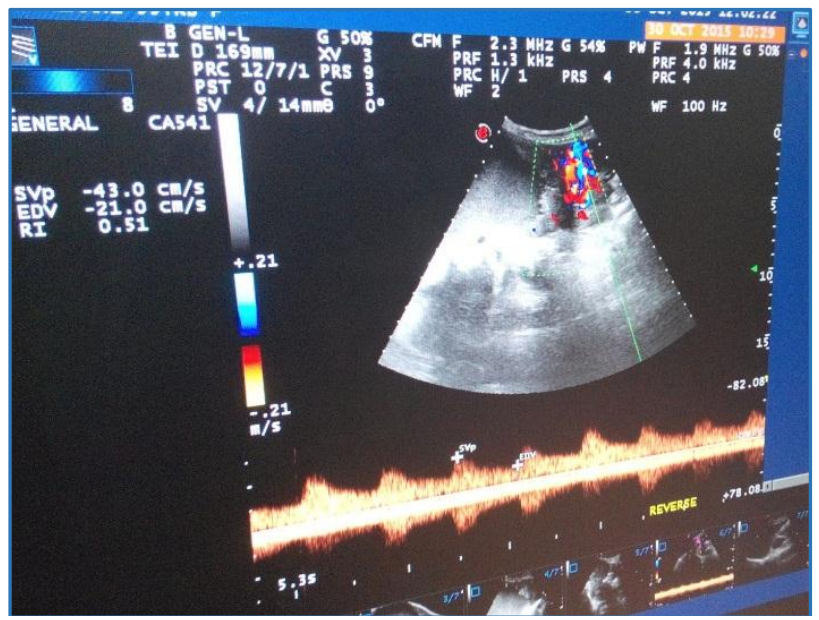

Fig. 5: A Case of Mucinous Cystadenocarcinoma with Increased Flow in Septal and Central Regions with Increased Diastolic Flow

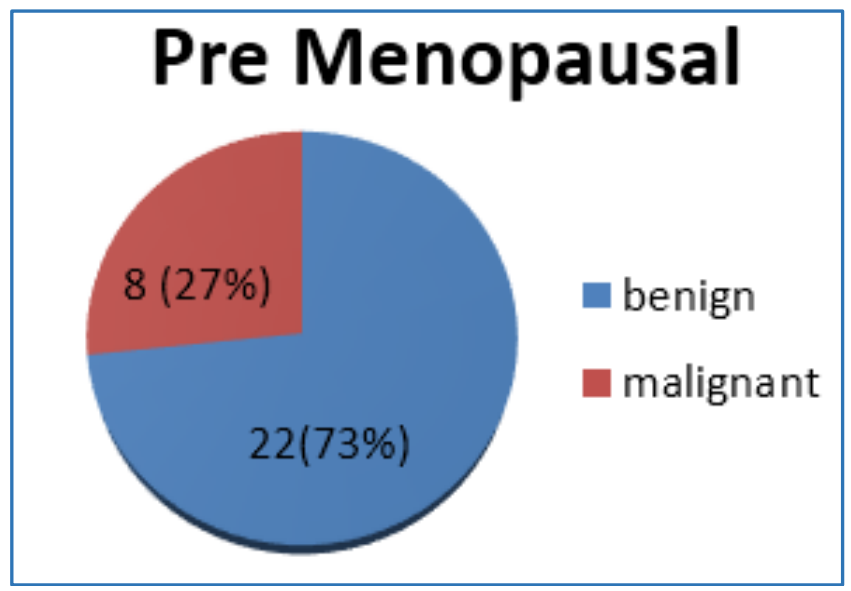

Fig. 6(a)

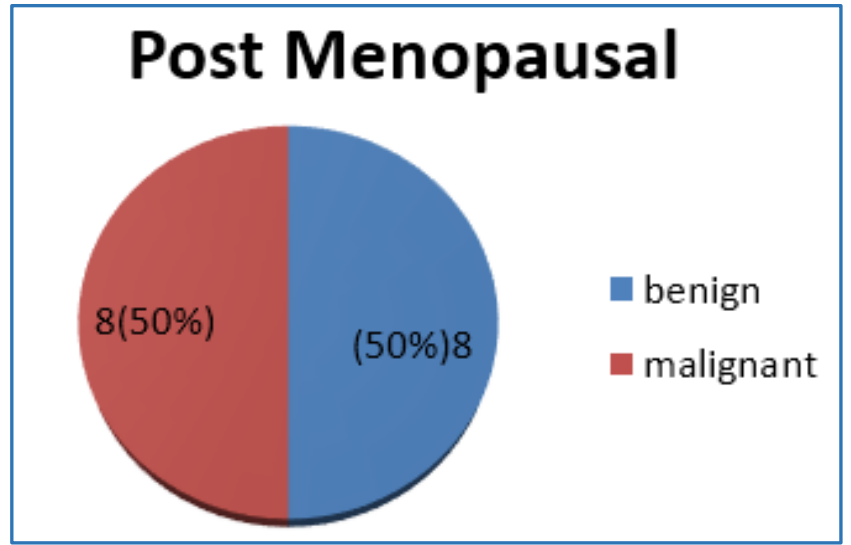

Fig. 6(b)

Fig. 6(a \& b): Pie-Chart showing the Incidence of Malignancy in Pre and Post Menopausal Age Group respectively. Inference(s): $50 \%$ of the Tumors in Post Menopausal Age Group are Malignant 


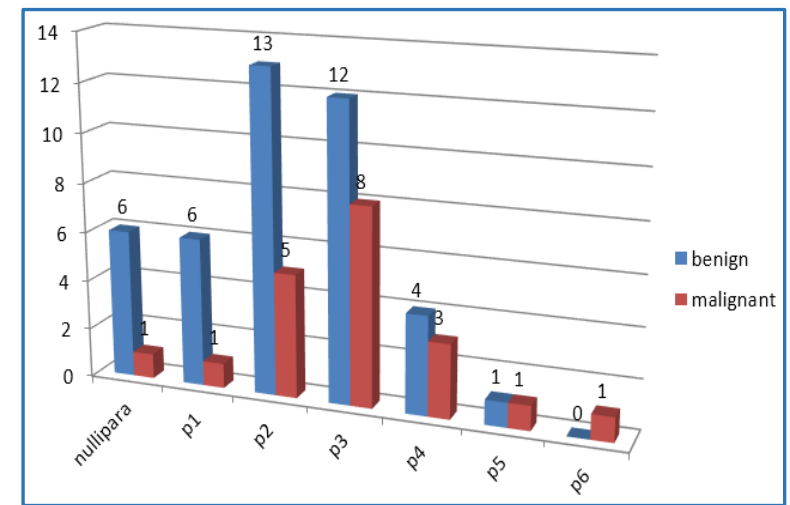

Fig. 7: Showing Incidence of Parity Both Malignant and Benign Masses are noted in Higher Numbers in p2 \& p3 Women.

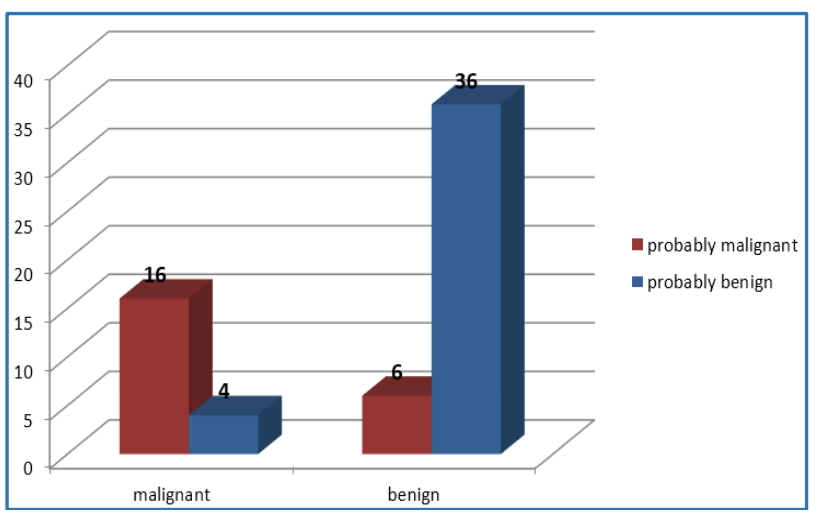

Fig. 8: Bar-Chart showing Predictive Value of Combination of Grayscale and Doppler Compared to Histopathology

Performance of ultrasound and Doppler in various studies.

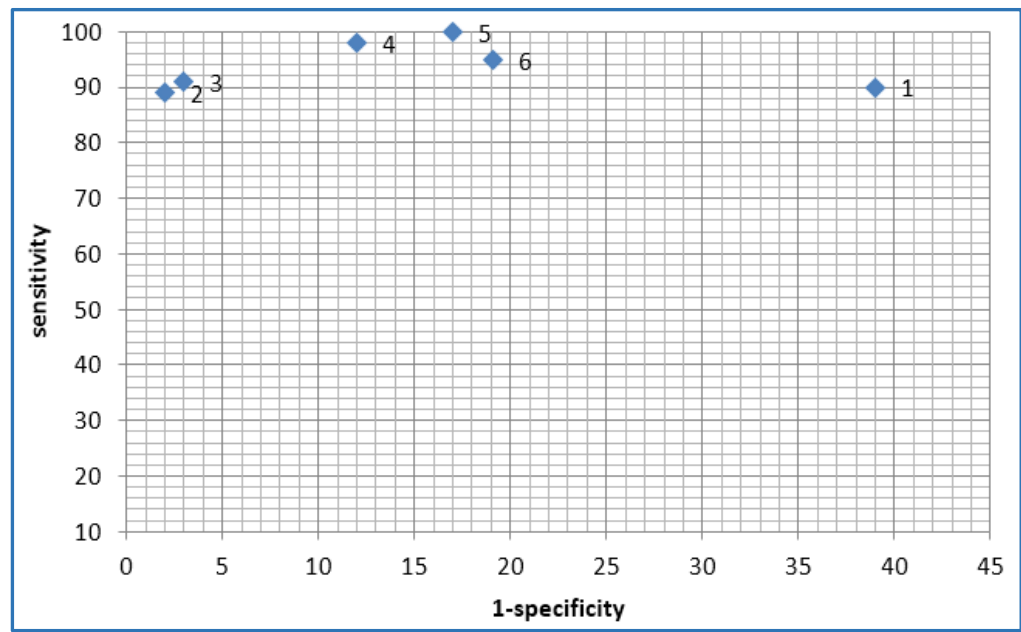

Fig. 9: 1=alcazar et al. (2003); 2=kurjak and kupesic (1999); 3=kurjak et al. (2000); 4=alcazar\&Castillo (2005); 5=veunto et al.; 6= our study (2013-15).

\section{REFERENCES}

1. Uma S, Neera K, Ektan. Evaluation of new scoring system to differentiate between benign and malignant adnexal mass. J Obstetrics gynecol India 2006;56;162-5.

2. Padilla LA, Radosevich DM, Milad MP. Accuracy of the pelvic examination in detecting adnexal masses. Obstet Gynecol 2000;96:593-8.

3. Vernooij F, Heintz P, Witteveen E, Van Der Graaf Y. The outcomes of ovarian cancer treatment are better when provided by gynecologic oncologists and in specialized hospitals: a systematic review. Gynecol Oncol 2007;105:801-12.

4. Levine D, Asch E, Mehta TS, Broder J, O'Donnell C, Hecht JL. Assessment of factors that affect the quality of performance and interpretation of sonography of adnexal masses. J Ultrasound Med 2008;27:721-8.

5. Yazbek J, Raju SK, Ben-Nagi J, Holland TK, Hillaby K, Jurkovic D. Effect of quality of gynaecological ultrasonography on management of patients with suspected ovarian cancer: a randomised controlled trial. Lancet Oncol 2008;9:124-31.
6. Vuento MH, Pirhonen JP, Mäkinen JI, Laippala PJ, Grönroos M, Salmi TA. Evaluation of ovarian findings in asymptomatic postmenopausal women with color Doppler ultrasound. Cancer 1995;76:1214-8.

7. Prompeler HJ, Madjar H, Sauberbrei W. Classification of adnexal tumours by transvaginal colour doppler. Gynecol oncol 1996;175;97-104.

8. Kurjak A, Shalan H, Kupesic S, Kosuta D, Sosic A. An attempt to screen asymptomatic women for ovarian and endometrial cancer with transvaginal color and pulsed Doppler sonography. J Ultrasound Med 1994;13:295-301.

9. Hamper UM, Sheth S, Abbas FM, Rosenshein NB, Aronson D, Kurman RJ. Transvaginal color Doppler sonography of adnexal masses: differences in blood flow impedance in benign and malignant lesions. AJR Am J Roentgenol 1993;160:1225-1228.

10. Stein SM, Laifer-Narin S, Johnson MB, Roman LD, Muderspach LI, Tyszka JM, Ralls PW. Differentiation of benign and malignant adnexal masses: relative value of gray-scale, color Doppler, and spectral Doppler sonography, American Journal of Roentgenology 02/1995;164(2):381-6. 
11. Madan R, Narula MK, Chitra R, Bajaj P. Sonomorphological and color doppler flow imaging evaluation of adnexal masses. Indian J Radiol Imaging 2004;14:365-72.

12. Macroscopic characterization of ovarian tumors and the relation to the histological diagnosis: criteria to be used for ultrasound evaluation. Gynecol Oncol 1989;35:139-144.

13. Benign and malignant ovarian masses: selection of the most discriminating gray-scale and Doppler sonographic features. Radiology 1998;208:103-110.

14. Terms, definitions and measurements to describe the sonographic features of adnexal tumors: a consensus opinion from the International Ovarian Tumor Analysis (IOTA) Group. Ultrasound Obstet Gynecol 2000;16:500-505.

15. Timmerman D, Valentin L, Bourne TH, et al.: Terms, definitions and measurements to describe the sonographic features of adnexal tumors: a consensus opinion from the International Ovarian Tumor Analysis (IOTA) group. Ultrasound Obstet Gynecol 16:500, 2000.

16. Granberg S, Wikland M, Jansson I: Macroscopic characterization of ovarian tumors and the relation to the histological diagnosis: criteria to be used for ultrasound evaluation. Gynecol Oncol 35:139,1989.

17. Granberg S, Norström A, Wikland M: Tumors in the lower pelvis as imaged by vaginal sonography. Gynecol Oncol 37:224, 1990.

18. Timmerman D, Bourne TH, Tailor A, et al.: A comparison of methods for preoperative discrimination between malignant and benign adnexal masses: the development of a new logistic regression model. Am J Obstet Gynecol 181:57, 1999.

19. Marret H, Ecochard R, Giraudeau B, et al.: Color Doppler energy prediction of malignancy in adnexal masses using logistic regression models. Ultrasound Obstet Gynecol 20:597, 2002.
20. Alcazar JL, Merce LT, Laparte C, et al.: A new scoring system to differentiate benign from malignant Gynecol 188:685, 2003.

21. Farnaz, Wahab S, Hassan L. Women with Ovarian Masses. J Postgrad Med Inst 2012;26(1):73-78.

22. Moon WJ, Koh BH, Kim SK, et al. Brenner tumor of the ovary: CT and MR findings. J Comput Assist Tomogr 2000;24:72-76.

23. Use of morphology to characterize and manage common adnexal masses. Best Pract Res ClinObstetGynaecol 2004;18:71-89.

24. Fleischer AC, Rodgers WH, Kepple DM, Williams LL, Jones HW, III. Color Doppler sonography of ovarian masses: a multiparameter analysis. J Ultrasound Med 1993;12:41-48.

25. Kupesic S, Kurjak A. Contrast enhanced threedimensional power Doppler sonography for the differentiation of adnexal masses. Obstet Gynecol 2000;96:452-58.

26. Fleischer AC, Pairleitner H. Transvaginal Doppler assesses ovarian flow. Diagn Imag 1998;9:47.

27. Fleischer AC, Pairleitner H. 3D transvaginal color Doppler sonography: Current and potential applications. Med Imag Int 1999;9:10-13.

28. Pairleitner H, Steiner H, Hasenoehrl G, Staudach A. Three-dimensional power Doppler sonography: Imaging and quantifying blood flow and vascularization. Ultrasound Obstet Gynecol 1999;14:139-43

29. Fleischer AC, Lyshchik A, Andreotti RF, et al. Advances in sonographic detection of ovarian cancer: depiction of tumor neovascularity with microbubbles. AJR Am J Roentgenol 2010;194:343-8.

30. Deshpande N, Ren Y, Foygel K, et al. Tumor angiogenic marker expression levels during tumor growth: Longitudinal assessment with molecularly targeted microbubbles and US imaging. Radiology 2011;258:804-11. 